\title{
Diaphragmatic fenestration for refractory chylothorax after congenital cardiac surgery in infants
}

\author{
T. K. Susheel Kumar, MD, ${ }^{\mathrm{a}}$ Kaitlin Balduf, MD, ${ }^{\mathrm{b}}$ Umar Boston, MD, ${ }^{\mathrm{a}}$ and Christopher Knott-Craig, $\mathrm{MD}^{\mathrm{a}}$
}

\section{ABSTRACT}

Objective: Medically refractory chylous pleural effusion after congenital heart surgery is associated with significant morbidity and mortality, especially in infants. We reviewed our experience with diaphragmatic fenestration procedure in this group of patients.

Methods: A retrospective chart review of all patients who had diaphragmatic fenestrations for chylous effusion at our institution over a 2-year period was performed.

Results: A total of 9 diaphragmatic fenestration procedures were performed in 8 patients who had failed medical management of chylous pleural effusions. All procedures except 1 were performed on the right side. The median age at time of procedure was 4.6 months (range, 3 weeks to 14 months). The average time between primary congenital cardiac surgery and fenestration was 26 days (range, 453 days). Three patients had single ventricle repair. Average time of chest tube removal after procedure was 4 days. Average time to extubation was 3 days. All patients but 1 were able to advance to full feedings without reaccumulation of chylous effusion within 12 days. No complications developed in the patients. Recurrent effusion over a median follow-up period of 19 months did not develop in the patients.

Conclusions: Diaphragmatic fenestration is an effective and safe strategy for management of persistent chylous effusions after congenital cardiac surgery. ( $\mathrm{J}$ Thorac Cardiovasc Surg 2017;154:2062-8)

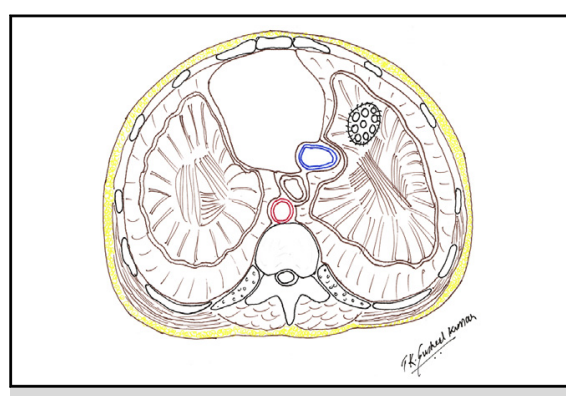

Diaphragmatic fenestration. Fenestrated polytetrafluoroethylene patch is sutured to the defect.

\section{Central Message}

Diaphragmatic fenestration is a safe and effective procedure for persistent chylous effusions in infants after congenital cardiac surgery.

\section{Perspective}

Persistent chylous effusions contribute to significant morbidity and mortality after surgical repair of congenital heart defects. Diaphragmatic fenestration is a safe and effective surgical technique for infants with persistent chylous effusions after cardiac surgery. It allows for timely reinitiation of enteral feedings, minimizing the period of suboptimal nutrition in these patients.

See Editorial Commentary page 2069.
Chylous pleural effusions or chylothorax is a welldescribed postoperative complication occurring in approximately $0.5 \%$ to $2 \%$ of patients after repair of congenital heart defects, with some reports documenting rates as high as $6.5 \% .^{1}$ Chylous effusions can lead to significant morbidity related to the fluid losses into the pleural space, including respiratory distress, malnutrition, and

From the Departments of ${ }^{\mathrm{a} P e d i a t r i c ~ C a r d i o t h o r a c i c ~ S u r g e r y ~ a n d ~}{ }^{\mathrm{b}}$ Pediatric Cardiology, Le Bonheur Children's Hospital and University of Tennessee Health Science Center, Memphis, Tenn.

Received for publication March 8, 2017; revisions received July 14, 2017; accepted for publication Aug 9, 2017; available ahead of print Sept 12, 2017.

Address for reprints: T. K. Susheel Kumar, MD, Department of Pediatric Cardiothoracic Surgery, Le Bonheur Children's Hospital, University of Tennessee Health Science Center, Memphis, TN 38103 (E-mail: tskumar@uthsc.edu). 0022-5223/\$36.00

Copyright (c) 2017 by The American Association for Thoracic Surgery http://dx.doi.org/10.1016/j.jtcvs.2017.08.002 immunologic compromise. $^{2-4}$ Current medical management revolves around dietary modifications, enteral rest, and octreotide. When medical management fails, surgical intervention in the form of thoracic duct ligation, pleurodesis, or pleuroperitoneal shunts becomes necessary. ${ }^{5-7}$ Fenestration of the diaphragm has been described as an effective strategy to treat resistant chylous effusions among older children after single or 2-ventricle repair. ${ }^{8,9}$ We describe our experience with this procedure

- Scanning this $\mathrm{QR}$ code will take you to a supplemental video for the article.

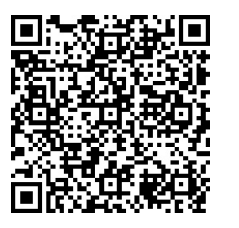




\section{Abbreviation and Acronym \\ $\mathrm{MCT}=$ medium chain triglyceride}

in a predominantly infant population with refractory chylous effusion after congenital cardiac surgery.

\section{MATERIAL AND METHODS \\ Patients}

The University of Tennessee Health Science Center Institutional Review Board approved this study. We performed a retrospective chart review over a 2-year period of 8 patients with documented refractory pleural chylous effusions to describe our experience with diaphragmatic fenestration. Patients with left chylous effusion resulting from direct injury to the thoracic duct or lymphatic channels during repair of coarctation or closure of patent ductus arteriosus were excluded from the study. These patients were managed by thoracic duct ligation via left thoracotomy.

\section{Methods}

The diagnosis of chylous pleural effusion was made on the basis of the characteristic milky appearance of fluid draining through the chest tube. This was confirmed by laboratory tests of the fluid that demonstrated characteristic features, including elevated triglyceride and lactate dehydrogenase levels, as well as lymphocytic predominance. All patients in whom chylous effusions developed received echocardiogram and Doppler of the neck to rule out thrombosis or external compression of the superior vena cava or its tributaries. Once a diagnosis of chylous effusion was confirmed, medical measures were initiated. Our institutional management algorithm for chylous effusions begins with dietary change to medium chain triglyceride (MCT) diet with transition to complete parenteral nutrition after 5 days if there is no improvement. If there are continued chylous losses prednisone and octreotide are used. Generally, 3 to 4 weeks of medical management is attempted before considering surgical intervention (Figure 1). Diaphragmatic fenestration was considered when patients failed medical management and continued to have more than $10 \mathrm{~mL} / \mathrm{kg} /$ $\mathrm{d}$ of chylous drainage. Complete hemodynamic assessment using transthoracic echocardiogram or cardiac catheterization was performed on every patient to rule out significant residual defects. A clinical examination of the abdomen followed by an ultrasound sonography of the abdomen was performed to rule out ascites on any patient considered for diaphragmatic fenestration.

\section{Surgical Technique}

After induction of anesthesia and placement of venous access, the patient was placed in a left lateral decubitus position with the right side up (Video 1). The chest and flank were then prepped and draped. The procedure began by placement of an oblique incision over the anterolateral portion of the right chest. The right chest was entered through the fifth or sixth intercostal space. After release of pleural adhesions, the right lung was retracted gently to expose the right hemidiaphragm (Figure 2). The anterior portion of the right hemidiaphragm was chosen for siting the fenestration. A circular portion of the diaphragm measuring approximately $2 \mathrm{~cm}$ in diameter was excised using cautery. Care was taken to avoid injury to the liver. The abdomen was then entered gently using a finger. Usually, there was a natural entry without the need for taking down any other ligaments of the liver. A patch of polytetrafluoroethylene (Gore-Tex; WL Gore \& Associates Inc, Flagstaff, Ariz) was then tailored to match the defect. The patch measured approximately $2 \mathrm{~cm}$ in diameter and $0.4 \mathrm{~mm}$ in thickness. A 3-mm aortic punch was used to create approximately 8 to 10 fenestrations (each measuring $3 \mathrm{~mm}$ in diameter) in the patch. This fenestrated patch was then used to close the defect using running 5.0 Prolene suture. In most patients, the pleural surface was covered by proteinaceous deposits making visualization of the thoracic duct difficult, and thus no attempt was made to ligate the thoracic duct. A chest tube was

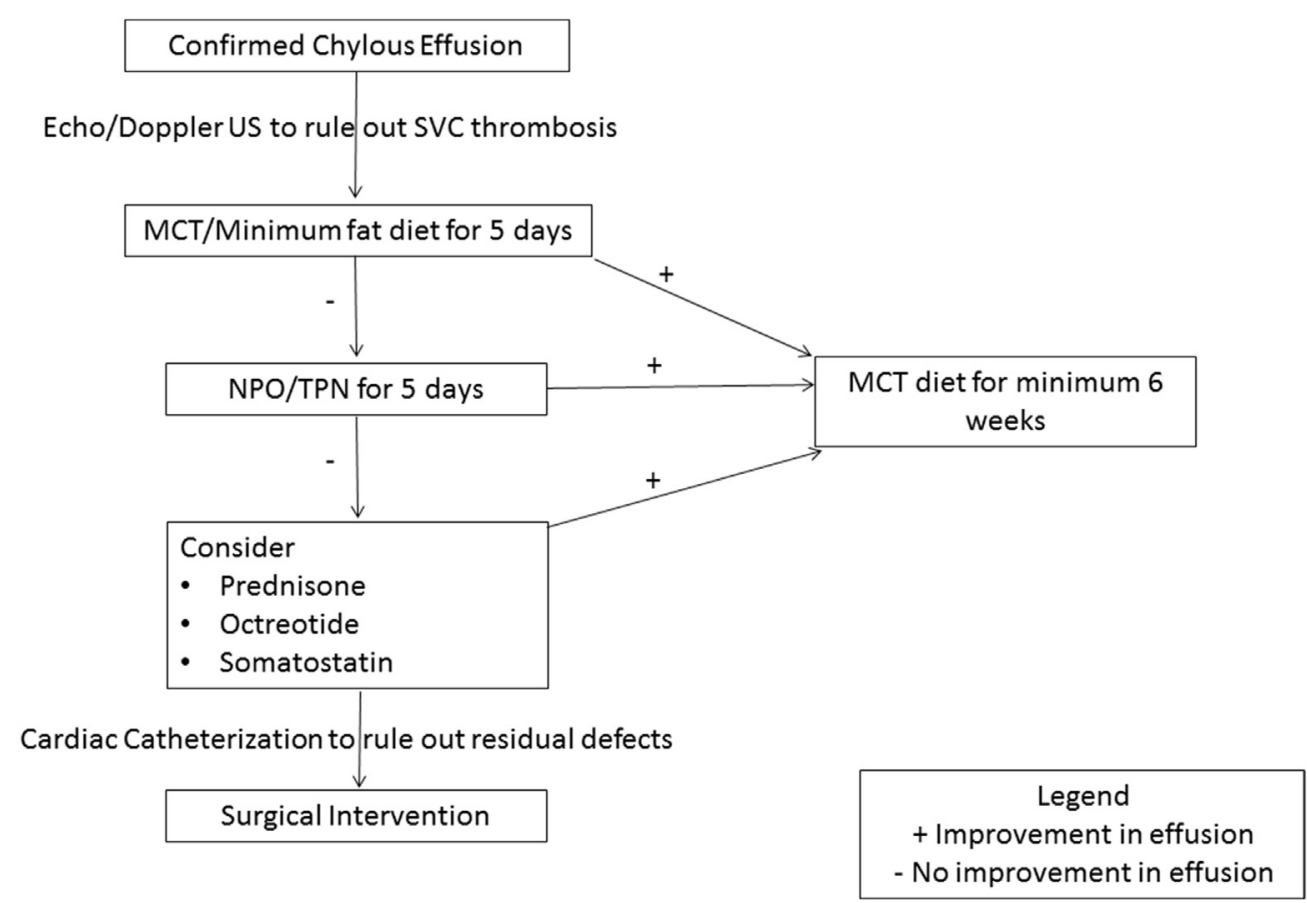

FIGURE 1. Simplified algorithm showing our institutional approach to postoperative chylous effusion. Surgical intervention depends on mechanism of chylothorax and could include diaphragmatic fenestration or thoracic duct ligation. US, Ultrasound; SVC, superior vena cava; $M C T$, medium chain triglyceride; $N P O$, nil per oral; $T P N$, total parenteral nutrition. 


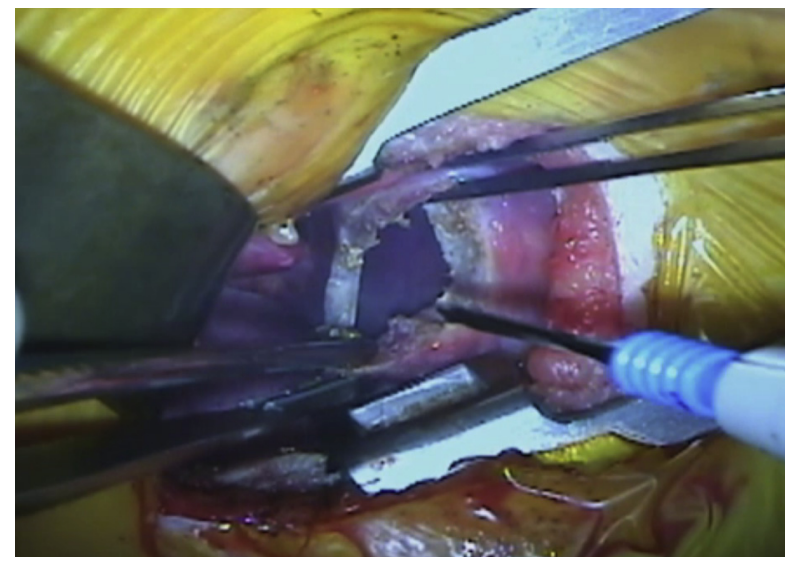

VIDEO 1. Surgical technique of diaphragmatic fenestration for refractory chylous effusion after congenital heart surgery in infants. Video available at: http://www.jtcvsonline.org/article/S0022-5223(17)31720-8/fulltext.

then placed, and the chest was closed in a standard manner. Postoperatively, the chest tube was watched for drainage and the abdomen for any distension. The chest tube was removed when the drainage was minimal and the abdomen did not show any signs of ileus from peritoneal entry. The diuretics were adjusted accordingly.

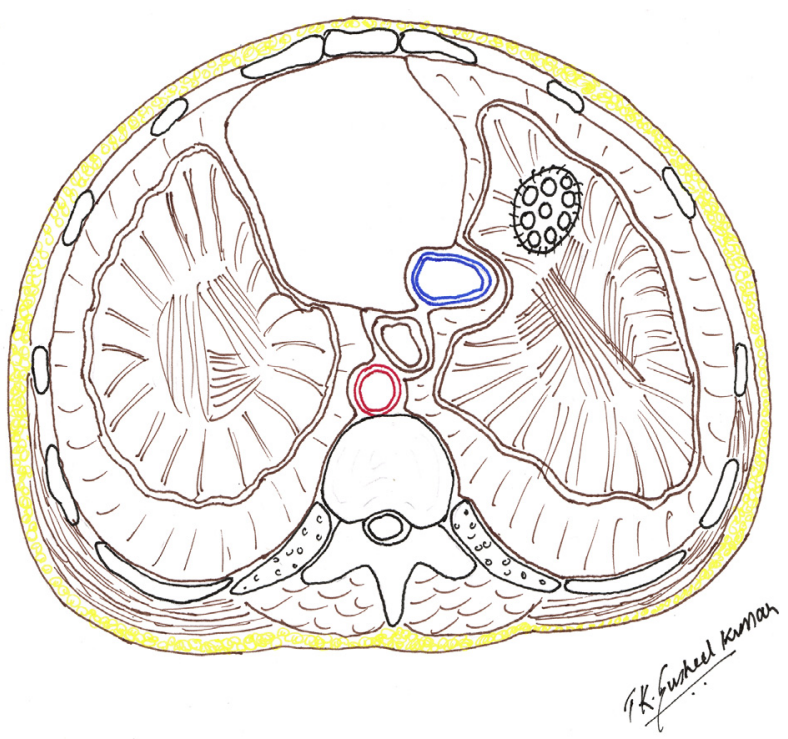

FIGURE 2. Technique of diaphragmatic fenestration. An appropriately sized fenestrated polytetrafluoroethylene patch is sutured to the margins of the defect using running Prolene suture.

TABLE 1. Summary of patients undergoing diaphragmatic fenestration for persistent chylous effusion

\begin{tabular}{|c|c|c|c|c|c|}
\hline Patient & $\begin{array}{l}\text { Age }(\mathrm{mo}) / \text { gender} / \\
\text { weight }(\mathbf{k g})\end{array}$ & $\begin{array}{l}\text { Gestational } \\
\text { age }\end{array}$ & Diagnosis & Additional diagnosis & Procedure/age at surgery (mo) \\
\hline 1 & $0.7 / \mathrm{male} / 3.38$ & 38 wk & Unguarded TV, PA, PAPVR & Chronic lung disease & BT shunt with atrial septectomy $/ 0.16$ \\
\hline 2 & $2.5 / \mathrm{male} / 3.9$ & $35 \mathrm{wk}$ & VSD & Trisomy 21 & Patch repair of VSD/2 \\
\hline 3 & $14 / \mathrm{male} / 7.28$ & $29 \mathrm{wk}$ & ASD, PS & Chronic lung disease & $\begin{array}{l}\text { Patch closure ASD, open pulmonary } \\
\text { valvotomy and MPA augmentation/14 }\end{array}$ \\
\hline 4 & $3 /$ female/3.5 & $35 \mathrm{wk}$ & VSD & Chronic lung disease & Patch closure of large inlet VSD/3 \\
\hline 5 & 7/female/6.3 & $39 \mathrm{wk}$ & $\begin{array}{l}\text { TOF, Balanced complete AV } \\
\text { canal type C }\end{array}$ & Trisomy 21 & $\begin{array}{l}\text { 2-patch repair of AVC with transannular } \\
\text { patch repair of TOF w/patch augmentation } \\
\text { of MPA/6 }\end{array}$ \\
\hline 6 & $5 / \mathrm{male} / 7.2$ & $39 \mathrm{wk}$ & $\begin{array}{l}\text { Large VSD, hypoplastic } \\
\text { aortic arch w/coarctation } \\
\text { hypoplastic RV }\end{array}$ & $\begin{array}{l}\text { Dysphagia, feeding } \\
\text { difficulties }\end{array}$ & Bidirectional Glenn/3.5 \\
\hline 7 & $1.5 /$ female/4 & $39 \mathrm{wk}$ & HLHS (MS/AA) & $\begin{array}{l}\text { Noncompaction of } \\
\text { single RV }\end{array}$ & Norwood/Sano/0.1 \\
\hline 8 & $4 / \mathrm{male} / 4.2$ & $33 \mathrm{wk}$ & Complete AV canal, type A & $\begin{array}{l}\text { Trisomy } 21, \text { Chronic } \\
\text { lung disease }\end{array}$ & 2 patch repair of AVC, closure of PDA/3 \\
\hline 8 & $4.5 / \mathrm{male} / 4.3$ & $33 \mathrm{wk}$ & Complete AV canal, type A & $\begin{array}{l}\text { Trisomy } 21 \text {, Chronic } \\
\text { lung disease }\end{array}$ & 2 patch repair of AVC, closure of PDA/3 \\
\hline
\end{tabular}

$T V$, Tricuspid valve; $P A$, pulmonary atresia; $P A P V R$, partial anomalous pulmonary venous return; $B T$, Blalock Taussig; $V S D$, ventricular septal defect; $R V S P$, right ventricular systolic pressure; $A S D$, atrial septal defect; $P S$, pulmonary stenosis; $M P A$, main pulmonary artery; $T R$, tricuspid regurgitation; $T O F$, tetralogy of Fallot; $A V$, arteriovenous; $A V C$, atrioventricular canal; $R V$, right ventricle; $H L H S$, hypoplastic left heart syndrome; $M S / A A$, mitral stenosis/aortic atresia; $N A$, not available; $P D A$, patent ductus arteriosus. 


\section{RESULTS}

The 8 patients consisted of 3 girls and 5 boys, most of whom were infants. A total of 9 diaphragmatic fenestration procedures were performed. The patients in our experience were significantly younger than in prior reports. ${ }^{8-10}$ Our 8 patients included 6 infants aged less than 6 months, the youngest being 22 days old at the time of procedure. The mean age of our population at time of fenestration was 4.5 months, ranging from 22 days to 14.25 months. Without accounting for 1 toddler, the mean age of patients at the time of procedure was 3.5 months, ranging from 22 days to 7 months. $50 \%$ of the patients had chronic lung disease and $40 \%$ had trisomy 21 . Some $80 \%$ of our population had trisomy 21 or chronic lung disease. In our patient group, 5 underwent biventricular repair and 3 are undergoing univentricular palliation (Table 1). The mean age at primary cardiac surgery was 4 months, ranging from 3 days to 14 months. The average time between cardiac surgery and diaphragmatic fenestration was 26 days, ranging from 4 to 53 days. All of the fenestrations were performed on the right side, with 1 patient requiring bilateral fenestrations. The effusion was bilateral in all but 1 patient (isolated right chylous effusion) with right-sided effusion being dominant. Patients were diagnosed with chylous effusion on the basis of characteristic milky appearance of pleural fluid and increase in volume upon initiation of enteral feedings. All effusions were confirmed by laboratory evaluation.

The average time of chest tube removal after the procedure was 4 days, ranging from 1 to 11 days. The need for mechanical ventilator support was on average 4.25 days before diaphragmatic fenestration and 3.25 days after fenestration. Radiologic resolution was usually slightly delayed on average requiring 5 days for right-sided clearance. Fullvolume enteral feedings were attained by all after diaphragmatic fenestration except for 1 patient with a complex single ventricle repair who had significant heart failure and bowel edema, which has prohibited full feedings to date. The average time to reach full feedings was 11.5 days, ranging from 2 to 40 days (Table 1). Of note, the patient who required 40 days to attain full enteral feedings had significant hospital course including chronic lung disease confounded by pneumonia that prohibited feeding for a prolonged period of time. Not accounting for the outliers, the other 6 patients were able to achieve full feeds within 2 weeks of their diaphragmatic fenestration. During a

TABLE 1. Continued

\begin{tabular}{|c|c|c|c|c|}
\hline Side of effusion & Echocardiography/catheter findings before procedure & $\begin{array}{l}\text { Interval between } \\
\text { initial surgery and } \\
\text { diagnosis/side of } \\
\text { fenestration }\end{array}$ & $\begin{array}{l}\text { Chest tube } \\
\text { removal after } \\
\text { fenestration }(d)\end{array}$ & $\begin{array}{l}\text { Time to } \\
\text { full feedings }\end{array}$ \\
\hline $\begin{array}{l}\text { Bilateral } \\
\text { right }>\text { left }\end{array}$ & $\begin{array}{l}\text { Unrestricted atrial septal communication. BT shunt and branch pulmonary } \\
\text { arteries patent. Systemic single ventricle pressure (echocardiography) }\end{array}$ & $17 \mathrm{~d} /$ right & 5 & $40 \mathrm{~d}$ \\
\hline $\begin{array}{l}\text { Bilateral } \\
\text { right }>\text { left }\end{array}$ & Tiny residual VSD. RVSP estimate $1 / 2$ systemic (echocardiography). & $6 \mathrm{~d} /$ right & 6 & $6 \mathrm{~d}$ \\
\hline Right & $\begin{array}{l}\text { Tiny additional atrial level defect with bidirectional shunting. Mild residual } \\
\text { pulmonary stenosis. Insufficient TR to estimate RVSP } \\
\text { (echocardiography). }\end{array}$ & $4 \mathrm{~d} /$ right & 11 & $10 \mathrm{~d}$ \\
\hline Right & No residual VSD. RVSP estimated at $1 / 2$ systemic (echocardiography). & $21 \mathrm{~d} /$ right & 3 & $4 \mathrm{~d}$ \\
\hline $\begin{array}{l}\text { Bilateral } \\
\text { right }>\text { left }\end{array}$ & $\begin{array}{l}\text { Tiny residual atrial communication and tiny ventricular septal defect. } \\
\text { Insufficient TR to estimate RVSP (echocardiography). }\end{array}$ & $19 \mathrm{~d} /$ right & 4 & $2 \mathrm{~d}$ \\
\hline $\begin{array}{l}\text { Bilateral } \\
\text { right }>\text { left }\end{array}$ & $\begin{array}{l}\text { Normal Glenn pressures. No aortopulmonary collaterals (cardiac } \\
\text { catheterization). }\end{array}$ & $53 \mathrm{~d} /$ right & 1 & $5 \mathrm{~d}$ \\
\hline $\begin{array}{l}\text { Bilateral } \\
\text { right }>\text { left }\end{array}$ & $\begin{array}{l}\text { Sano shunt patent, aortic arch unobstructed, innominate vein patent. Normal } \\
\text { single RV function (cardiac catheterization) }\end{array}$ & $41 \mathrm{~d} /$ right & 3 & NA \\
\hline $\begin{array}{l}\text { Bilateral } \\
\text { right }>\text { left }\end{array}$ & $\begin{array}{l}\text { Small atrial fenestration with right to left shunting. Tiny residual VSD with } \\
\text { bidirectional shunting. RVSP estimated at } 80 \mathrm{~mm} \mathrm{Hg} \text { (echocardiography) }\end{array}$ & $27 \mathrm{~d} /$ right & 1 & $14 \mathrm{~d}$ \\
\hline Left & $\begin{array}{l}\text { Small atrial fenestration, right to left shunting. Tiny residual VSD with left } \\
\text { to right shunting. RVSP estimated at } 65 \mathrm{~mm} \mathrm{Hg} \text { (echocardiography) }\end{array}$ & $42 \mathrm{~d} / \mathrm{left}$ & 2 & $11 \mathrm{~d}$ \\
\hline
\end{tabular}


median follow-up period of 19 months, there was no return of effusion in any patient and ascites did not develop in any patient. Phrenic nerve palsy or wound issues did not develop in any patient.

\section{Comment}

Chylothorax is a dreaded complication after congenital cardiac surgery with potential for significantly increased morbidity. ${ }^{2}$ The incidence of chylothorax ranges from $0.5 \%$ to $2 \%,{ }^{3,5}$ with some reporting an incidence as high as $9 \%$ after congenital cardiac surgery. ${ }^{1,11}$ Because of the associated fluid losses, in particular the loss of proteins and immunoglobulins, patients with persistent chylothorax often experience marked respiratory compromise with increased risk of infection and sepsis, as well as malnutrition. 2,3,7 Chylothorax results from damage to the thoracic tract or its draining lymphatic channels, the cause of which can be grouped into 5 main categories, including congenital, traumatic, high central venous pressure, malignancy, and miscellaneous. ${ }^{7}$

Standard management has included medical management and surgical or cardiac catheterization interventions when medical management fails. Conservative treatment entails the use of a MCT enriched diet or parenteral nutrition. Compared with long chain triglycerides, MCT directly enters the portal circulation with minimal creation of chylomicrons, thereby minimizing lymphatic fluid. ${ }^{11}$ Alternatively, total parenteral nutrition can be used in those with failure of MCT-enriched diets. ${ }^{1}$ Medical management options include the use of somatostatin or its analog octreotide. The use of octreotide has shown some benefit in patients after coronary artery bypass grafting ${ }^{12}$ but only occasional benefit in children undergoing cardiac surgery. ${ }^{13-15}$

If chylothorax continues to be unresponsive to initial medical management, intervention with cardiac catheterization in form of balloon angioplasty, stent implantation or atrial fenestration can be considered. In cases of superior vena cava syndrome endovascular intervention with local administration of tissue plasminogen activator and balloon angioplasty with or without stent implantation have shown to be effective in older children and adults ${ }^{16,17}$ but with limited success in infants. Interatrial fenestration has been described to relieve elevated atrial pressures, ${ }^{18}$ but has not been described in the setting of chylous effusion. Recent developments in lymphangiography and lymphatic intervention while promising for repair of lymphatic flow problems are not widely available techniques. ${ }^{19}$

Traditionally, surgical interventions have included thoracic duct ligation, pleurodesis, or creation of a pleuroperitoneal shunt. A recent report demonstrated the successful use of superior vena cava reconstruction for chylothorax secondary to superior vena cava thrombosis previously unresponsive to more conservative therapy. ${ }^{20}$ Surgical intervention has been reserved for patients who fail all conservative therapies with continued significant chylous leak beyond 4 weeks. ${ }^{11}$ Each of these surgical techniques has demonstrated efficacy and limitations of use. Thoracic duct ligation has been described in the literature as the most commonly used technique for chylothorax requiring surgical intervention. When the site of injury to the thoracic duct can be easily identified, this technique can be highly efficacious, for example, after coarctation repairs, complex aortic arch repairs, or placement of Blalock-Taussig shunt where the thoracic duct is in close proximity to the surgical site and can more frequently be damaged. When a distinct site of injury is not identifiable, thoracic duct ligation often fails (Table 2). An additional reason for failure of thoracic duct ligation is the variable anatomy with approximately half of the population demonstrating anatomic alternations, including duplications or triplications. ${ }^{3,6,7,21}$

Pleurodesis, the chemical or surgical obliteration of the pleural space, has been used in cases of resistant chylothorax where thoracic duct ligation is not attempted., Although chemical pleurodesis is a safe and attractive alternative in neonatal patients because it can be accomplished via a minimally invasive procedure, it has mixed efficacy, with some reports documenting the need for multiple interventions. The well-documented significant pain associated with pleurodesis and the potential for respiratory compromise, lymph edema, and pulmonary fibrosis present a significant risk to patients with comorbid congen-

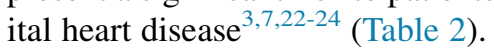

Pleuroperitoneal shunts have been efficacious in infants, with limited data of use in older children. A report by Engum and colleagues ${ }^{24}$ demonstrated the effectiveness of pleuroperitoneal shunts in the neonatal population for refractory chylothorax, of both congenital and postsurgical causes. ${ }^{24}$ Although there seems to be more extensive use for this form of intervention, they require daily pumping and a patent inferior vena cava, and are less efficacious in patients in whom the right atrial pressure is elevated (Table 2). Reports have demonstrated that the shunts must remain in place for up to 2.5 months to maintain freedom from reaccumulation of effusion. ${ }^{7,11,24}$

Superior vena caval thrombectomy and reconstruction as a procedure is effective in a specialized group of patients. Kumar and colleagues ${ }^{20}$ described 4 patients with documented thrombosis of the superior vena cava who underwent open thrombectomy and reconstruction using pulmonary homograft. However, cardiopulmonary bypass is required on compromised patients. ${ }^{20}$ Generally speaking, a comparison of surgical techniques is difficult because the surgical option is often targeted toward the underlying cause of the chylous effusion (thoracic duct injury, elevated central venous pressure, or thrombosis of the superior vena cava). ${ }^{7}$ 
TABLE 2. Comparison of various surgical techniques for refractory chylous effusion

\begin{tabular}{|c|c|c|}
\hline & Advantages & Disadvantages \\
\hline Thoracic duct ligation & $\begin{array}{l}\text { Ideal when site of damage to thoracic duct can be } \\
\text { precisely identified. }\end{array}$ & $\begin{array}{l}\text { Decreased efficacy in cases of diffuse chylous leak and } \\
\text { those due to elevated venous pressure. } \\
\text { Variable anatomy of thoracic duct in general population. }\end{array}$ \\
\hline Pleurodesis & $\begin{array}{l}\text { Chemical options allow for minimally invasive } \\
\text { procedure. }\end{array}$ & Associated pain, less well-proven efficacy. \\
\hline Pleuroperitoneal shunt & $\begin{array}{l}\text { Relatively simple technique. Can be used for those with } \\
\text { unclear site of chylous leak. }\end{array}$ & $\begin{array}{l}\text { Requires unobstructed venous system and daily } \\
\text { pumping. Potentially prolonged period of time shunt is } \\
\text { in place. } \\
\text { Less efficacious with elevated right atrial pressures. }\end{array}$ \\
\hline SVC thrombectomy & Ideal for patients with documented SVC occlusion. & $\begin{array}{l}\text { Only efficacious in patients with documented SVC } \\
\text { occlusive lesion as cause of chylous leak. }\end{array}$ \\
\hline Diaphragmatic fenestration & $\begin{array}{l}\text { Can be used in all patients with good success and } \\
\text { minimal procedural complications. } \\
\text { Suitable for both single and biventricular physiologies. } \\
\text { Demonstrated safety in infant population. } \\
\text { Effective in patients in whom site of damage to thoracic } \\
\text { duct is unknown or diffuse leak is suspected, and those } \\
\text { with elevated CVP. }\end{array}$ & $\begin{array}{l}\text { Cannot be used for patients with } \\
\text { - Peritonitis or ascites } \\
\text { - Malignant pleural effusion } \\
\text { - Peritoneal dialysis requirement }\end{array}$ \\
\hline
\end{tabular}

$S V C$, Superior vena cava; $C V P$, central venous pressure.

Diaphragmatic fenestration for persistent chylothorax was described by Durairaj and colleagues ${ }^{8}$ in 2002 with successful use in a 12-year-old patient after the Fontan operation. Later, Talwar and colleagues ${ }^{10}$ described the successful use of the technique in a series of patients with resistant pleural effusions after univentricular repair. ${ }^{8,10}$ The mean age of this population was 8.4 years +4.8 years. ${ }^{10}$

Previous reports on the use of diaphragmatic fenestration have been described predominantly for older children and adolescents, and for those undergoing univentricular repair. ${ }^{8-10}$ Our patients consisted of infants, predominantly less than 6 months old at the time of diaphragmatic fenestration. A significant portion of these patients had associated trisomy 21 , which is known to be associated with congenital abnormalities of the chyle system predisposing to chylothorax.

It is also interesting to note that all patients in our series underwent right-sided diaphragmatic fenestration, with only 1 patient requiring bilateral fenestration. In our population, we noted that although the majority of patients demonstrated bilateral effusions before the intervention, there was resolution of both right- and left-sided effusions with a single right-sided procedure. This is likely related to the interconnectivity of lymphatic drainage in the inferior tracheobronchial lymph nodes, which has been shown to receive drainage from both right and left lung segments with effluence to right or left paratracheal lymphatic trees. $^{25}$

Of our outcome evaluations, most notable is the relatively brief time period for resolution of effusion, the majority of which occurred within 5 days of diaphragmatic fenestration. The ability to attain full enteral feeding in all but 1 of our patients was another substantial indicator of the success of the procedure. The mean time to extubation was 3.25 days, although most patients had comorbidities such as chronic lung disease.

We have established the efficacy of this procedure in infants undergoing both univentricular palliation and biventricular repair. Although our patients had in some cases prolonged hospital courses, there were no complications associated with the procedure itself, including diaphragm paralysis, wound infection, or pneumothorax, indicating a satisfactory safety profile for the continued use of diaphragmatic fenestration in infants and toddlers. Although we encourage the initial use of medical management, given the significant comorbidities associated with persistent chylothorax we would advocate earlier definitive intervention. Of the available surgical options in the population of infants with congenital heart disease, diaphragmatic fenestration appears to be an ideal choice given the short time for resolution of effusion, rapid attainment of full enteral feedings, and the ability to perform safely in infants and toddlers who have undergone a wide variety of congenital cardiac repairs.

\section{Study Limitations}

This is a single institutional experience and may not be generalizable. Our patient population is small because this is an evolving technique. The follow-up of patients is limited, and thus the long-term outcomes of this procedure are not available. 


\section{CONCLUSIONS}

Diaphragmatic fenestration is an effective and safe strategy for the management of persistent chylous effusions after congenital cardiac surgery among infants.

\section{Conflict of Interest Statement}

Authors have nothing to disclose with regard to commercial support.

\section{References}

1. Biewer ES, Zurn C, Arnold R, Glockler M, Glöckler M, Schulte-Mönting J, et al. Chylothorax after surgery on congenital heart disease in newborns and infants- risk factors and efficacy of MCT-diet. J Cardiothorac Surg. 2010;5: 127.

2. Roehr CC, Jung A, Proquitte H, Blankenstein O, Hammer H, Lakhoo K, et al. Somatostatin or octreotide as treatment options for chylothorax in young children: a systematic review. Intensive Care Med. 2006;32:650-7.

3. Milonakis M, Chatzis AC, Giannopoulos NM, Contrafouris C, Bobos D, Kirvassilis GV, et al. Etiology and management of chylothorax following pediatric heart surgery. J Card Surg. 2009;24:369-73.

4. Talwar S, Agarwala S, Mittal CM, Choudhary SK, Airan B. Pleural effusions in children undergoing cardiac surgery. Ann Pediatr Cardiol. 2010;3:58-64.

5. Le Coultre C, Oberhänsli I, Mossaz A, Bugmann P, Faidutti B, Belli DC. Postoperative chylothorax in children: differences between vascular and traumatic origin. J Pediatr Surg. 1991;26:519-23.

6. Beghetti M, La Scala G, Belli D, Bugmann P, Kalangos A, Le Coultre C. Etiology and management of pediatric chylothorax. J Pediatr. 2000;136:653-8.

7. Soto-Martinez M, Massie J. Chylothorax: diagnosis and management in children. Paediatr Respir Rev. 2009;10:199-207.

8. Durairaj M, Sharma R, Choudhary SK, Bhan A, Venugopal P. Diaphragmatic fenestration for resistant pleural effusions after univentricular repair. Ann Thorac Surg. 2002;74:931-2.

9. Talwar S, Choudhary SK, Mukkannavar SB, Airan B. Diaphragmatic fenestration for resistant pleural effusions after the Fontan operation. J Thorac Cardiovasc Surg. 2012;143:244-5.

10. Talwar S, Das A, Choudhary SK, Airan B. Diaphragmatic fenestration for resistant pleural effusions after univentricular palliation. World J Pediatr Congenit Heart Surg. 2016;7:146-51.

11. Panthongviriyakul C, Bines JE. Post-operative chylothorax in children: an evidence-based management algorithm. J Paediatr Child Health. 2008;44:716-21.
12. Ismail NA, Gordon J, Dunning J. The use of octreotide in the treatment of chylothorax following cardiothoracic surgery. Interact Cardiovasc Thorac Surg. 2015;20:848-54.

13. Rimensberger PC, Müller-Schenker B, Kalangos A, Beghetti M. Treatment of a persistent postoperative chylothorax with somatostatin. Ann Thorac Surg. 1998; 66:253-4.

14. Pratap U, Slavik Z, Ofoe VD, Onuzo O, Franklin RC. Octreotide to treat postoperative chylothorax after cardiac operations in children. Ann Thorac Surg. 2001; 72:1740-2.

15. Lim KA, Kim SH, Huh J, Kang IS, Lee HJ, Jun TG, et al. Somatostatin for postoperative chylothorax after surgery for children with congenital heart disease. $J$ Korean Med Sci. 2005;20:947-51.

16. Rizvi AZ, Kalra M, Bjarnason H, Bower TC, Schleck C, Gloviczki P. Benign superior vena cava syndrome: Stenting is now the first line treatment. J Vasc Surg. 2008;47:372-80.

17. Rachapalli V, Boucher LM. Superior vena cava syndrome: role of the interventionalist. Can Assoc Radiol J. 2014;65:168-76.

18. Klepetko W, Mayer E, Sandoval J, Trulock EP, Vachiery JL, Dartevelle P, et al. Interventional and surgical modalities of treatment for pulmonary arterial hypertension. J Am Coll Cardiol. 2004;43(12 Suppl S):73S-80S.

19. Dori Y. Novel lymphatic imaging techniques. Tech Vasc Interv Radiol. 2016;19: 255-61.

20. Kumar TK, Subramanian S, Sathanandam S, Alexander J, Ali M, Knott-Craig CJ. Superior vena cava reconstruction for treatment of chylothorax resulting from thrombosis of superior vena cava in young infants. Ann Thorac Surg. 2015; 100:1432-6.

21. Buttiker V, Franconi S, Burger R. Chylothorax in children: guidelines for diagnosis and management. Chest. 1999;116:682-7.

22. Clive AO, Jones HE, Bhatnagar R, Preston NJ, Maskell N. Interventions for the management of malignant pleural effusions: a network meta-analysis. Cochrane Database Syst Rev. 2016;CD010529.

23. Brissaud O, Desfrere L, Mohsen R, Fayon M, Demarquez JL. Congenital idiopathic chylothorax in neonates: chemical pleurodesis with povidone-iodine (Betadine). Arch Dis Child Fetal Neonatal Ed. 2003;88:F531-3.

24. Engum SA, Rescorla FJ, West KW, Scherer LR III, Grosfeld JL. The use of pleuroperitoneal shunts in the management of persistent chylothorax in infants. $J$ Pediatr Surg. 1999;34:286-90.

25. Ndiaye A, Dimarino V, Ndiaye A, Gaye M, Ba PS, Nazarian S. Variations in lung lymphatic drainage into the inferior tracheobronchial lymph nodes junction: applications in lung cancer. Clin Anat. 2016;29:955-62.

Key Words: infants, postoperative, congenital, surgery

Readers who found these articles interesting may also like to read the following papers found in recent and future issues of our sister publications, Seminars in Thoracic and Cardiovascular Surgery and Operative Techniques in Thoracic and Cardiovascular Surgery!

\section{Congenital: Perioperative Management}

STATE OF THE ART: Corrected Article: Surgical Techniques for Repair of Peripheral Pulmonary Artery Stenosis Richard D. Mainwaring. Semin Thoracic Surg 2017: 198-205.

ORIGINAL SUBMISSION: Comparison of Del Nido and St Thomas Cardioplegia Solutions in Pediatric Patients: a Prospective Randomized Clinical Trial Sachin Talwar. Semin Thoracic Surg 2017: In press.

Editorial Commentary: Who Makes the Best Martini? Jonathan M. Chen. Semin Thoracic Surg 2017: In press.

ORIGINAL SUBMISSION: Right Ventricular Outflow Reconstruction Using a Polytetrafluoroethylene Conduit with Bulging Sinuses and Tricuspid Fan-Shaped Polytetrafluoroethylene Valve Masaaki Yamagishi. Oper Tech Thorac Cardiovasc 2016: 211-229. 